\title{
Article
}

\section{Keep/refer decision making abilities of European final year undergraduate physiotherapy students: A cross- sectional survey using clinical vignettes}

Lackenabuer, Wolfgang, Janssen, Jessica, Roddam, Hazel and Selfe, James

Available at http://clok.uclan.ac.uk/21054/

Lackenabuer, Wolfgang, Janssen, Jessica ORCID: 0000-0002-5961-2736, Roddam, Hazel ORCID: 0000-0002-0637-1801 and Selfe, James (2017) Keep/refer decision making abilities of European final year undergraduate physiotherapy students: A cross-sectional survey using clinical vignettes. European Journal of Physiotherapy . ISSN 2167-9169

It is advisable to refer to the publisher's version if you intend to cite from the work. http://dx.doi.org/10.1080/21679169.2017.1408682

For more information about UCLan's research in this area go to http://www.uclan.ac.uk/researchgroups/ and search for < name of research Group>.

For information about Research generally at UCLan please go to http://www.uclan.ac.uk/research/

All outputs in CLoK are protected by Intellectual Property Rights law, including Copyright law. Copyright, IPR and Moral Rights for the works on this site are retained by the individual authors and/or other copyright owners. Terms and conditions for use of this material are defined in the policies page. 


\section{Abstract}

Purpose

The recognition of pathological processes, which are not appropriate for physiotherapy, is a crucial part of the clinical reasoning process. Over recent years, there have been several research efforts investigating qualified physiotherapists and doctoral students' capability in making precise clinical decisions on whether a patient's condition is suitable for physiotherapy intervention (keep), or rather requires medical check-up (refer). No study so far has examined the keep/refer decision making abilities of final year undergraduate physiotherapy students within Europe.

Materials and Methods

A survey containing 12 validated vignettes was distributed among 2238 final year undergraduate physiotherapy students from 15 different member countries of the European Network of Physiotherapy in Higher Education (ENPHE).

Results

73 respondents were included in the final analysis. Only slightly more than half (mean: 53\%; median: $67 \%$ ) of the medical critical vignettes were answered correctly. Just eight respondents $(11 \%)$ correctly identified all three medical critical vignettes.

\section{Conclusion}

European final year undergraduate physiotherapy students are not sufficiently equipped with enough knowledge and skills to make very precise keep/refer decisions (based on clinical vignettes) and, most importantly, seem insufficiently trained to accurately identify more critical medical conditions which need a timely referral to another health care professional.

\section{Keywords}

Keep/refer decision, differential diagnosis, red flags, physiotherapy, medical referral.

\section{Main text introduction}

The recognition of serious pathologies which mimic more benign conditions of the musculoskeletal system is a challenging task for all health care professionals [1]. Despite several reports which emphasized the generally low prevalence of sinister conditions affecting the vertebral column (with a special focus on the lumbar region) [2-4], there are an abundance of case reports and case series within the current literature where physiotherapists recognised the presence of a wide range of different pathologies where medical attention was essential [5-10]. These cases and case series of serious pathologies highlight the need for 
physiotherapists to be able to determine if movement based, physiotherapy intervention is indicated (keep), or not (refer) [8].

Acknowledging the importance for physiotherapists to independently screen patients for the presence of serious medical diseases, the World Confederation of Physical Therapists (WCPT) Guidelines for Standards of Physical Therapy Practice [11] and the WCPT guideline for physical therapist professional entry level education [12] both require physiotherapists to know when a referral to another professional is warranted. Moreover, the WCPT guideline for physical therapist professional entry level education [12] specifically demand that a comprehensive review of various body systems (cardiovascular, pulmonary, musculoskeletal, neuromuscular, integumentary) has to be carried out as part of the patient's assessment. In addition, the WCPT policy statement for education expects that 'any programme, irrespective of its length and mode of delivery, should deliver a curriculum that will enable physical therapists to attain the knowledge, skills and attributes described in the guidelines for physical therapist professional entry level education' [13, p. 1].

Despite the requirements of the WCPT [11-13], a recent review by Lackenbauer et al. [14] revealed that there is a lack of overall consensus among various European countries to which extent (or even if) keep/refer decision making abilities are included in individual national educational and professional guidelines.

Over the past 13 years, there have been several studies investigating the clinical keep/refer decision making abilities (based on clinical vignettes) of qualified physiotherapists in the United States [15-17] of students who completed a professional doctorate (DPT) [18] in the United States and of qualified physiotherapists in Germany [19] and Switzerland [20]. Vignettes are concise (written) cases which describe a particular clinical presentation [21]. Results of these studies make it obvious that participants found it difficult to accurately detect the presence of conditions requiring medical attention [15-20]. Results also indicated that variables such as more years of work experience [18-20], additional/higher and specialized postgraduate education [16] and working in an outpatient setting [17] seem to improve the physiotherapist's ability to identify severe medical conditions which require a referral for further medical check-up.

To the present day, however, there is no data to show whether undergraduate physiotherapy programmes sufficiently prepare novice physiotherapists to make such important clinical (keep/refer) judgements when working with patients. The aim of the current research project 
was to analyse the keep/refer decision making abilities of final year undergraduate physiotherapy students who were, at the time of this project, studying at an ENPHE member institution.

\section{Materials and Methods}

In order to assess the keep/refer decision making abilities of European final year undergraduate physiotherapy students, a cross-sectional study using previously published and validated vignettes was carried out.

Ethical approval (Ethics Application 1390) was obtained from the Manchester Metropolitan University Ethics Committee (Faculty of Health, Psychology and Social Care).

A displayed in Figure 1, the target population for the current study involved final year undergraduate physiotherapy students from the 183 member Universities, in 28 European countries, as listed on the European Network of Physiotherapy in Higher Education (ENPHE) website. Forty-two Universities from 17 European countries replied to the formal invitation. However, six Universities had to be further excluded. As a consequence, 36 Universities (with a total number of 2238 final year undergraduate physiotherapy students) from 15 ENPHE member countries, as seen in Table 1, were finally included in the study and received (depending on individual graduation dates) an e-mail, which contained full study description together with the link for the survey, between May 2016 and February 2017. A total of 76 students from 10 different European countries completed the survey. Three additional students had to be excluded from the final analysis. Two students failed to complete all 12 cases and one student indicated to have completed his undergraduate degree in France (though no University from France took part in the study). In the end, 73 students (3.3\%) from 10 ENPHE member countries completed all 12 cases and were therefore included in the final analysis.

ENPHE member institutions were chosen as, on its homepage, the European Network of Physiotherapy in Higher Education advocates participation in European wide research projects which intend to compare and improve educational standards. Therefore, it was assumed that ENPHE member institutions (and students) were more likely to participate in the study than non ENPHE member Universities in Europe. 
In order to assess the keep/refer decision making abilities of European final year undergraduate physiotherapy students, an online survey containing 12 clinical vignettes was created. These vignettes have already been successfully used in previous studies on qualified physiotherapists in Switzerland [20], Germany [19] the United States [16] and on DPT students in the United States [18]. The clinical vignettes used (with permission) for the current project had already been validated on two separate occasions by expert physiotherapists [16] and a panel of medical doctors [18]. For more detailed information about case contents and case justification, the reader is referred to the original source by Jette et al. [16].

ENPHE member Universities were initially informed about the upcoming project during an ENPHE conference in autumn 2015. Concurrently, ENPHE University e-mail addresses were obtained from the official ENPHE homepage. Individual Universities were then contacted in written form in December 2015 (via e-mail) explaining the purpose of the project and inviting them to take part in the study. Those Universities that did not respond to the first e-mail received a second, identical invitation (via e-mail) at the end of January 2016. Responding Universities were asked to indicate their graduation date(s) to ensure that the distribution of the vignettes would take place as close as possible to the day of their graduation. There was no follow up and students received the link for the survey only once. Depending on the individual academic calendar of participating Universities, an e-mail containing full description of the study and the link for the survey was sent over the course of ten months between May 2016 and February 2017. To protect each individual student's identity, this email was initially sent to an official contact person from each University and then subsequently distributed among the final year undergraduate physiotherapy students. The full survey was online and password protected using the Bristol Online Survey Tool (BOS). Participating students were first asked to indicate the country where they completed their undergraduate degree. In line with earlier methodology [16-20] participating students were instructed to individually decide (based on the clinical situation described) either to start physiotherapy without additional medical evaluation (keep), treat the patient but also refer him/her for medical examination (keep and refer) or refer the patient for medical check-up without giving any physiotherapeutic intervention (refer). In accordance with Beyerlein [19], students were asked to complete the survey within 15 minutes. Only one answer option per question was possible. Individual case contents of the 12 vignettes were classified as:

- Musculoskeletal

- Medical non-critical 
- Medical critical.

Also replicating previously used methodology [16-20], a correct answer for the musculoskeletal cases was to treat the patient without the need for medical referral (keep) or to treat the patient with additional medical check-up (keep and refer). A correct answer for the medical non-critical cases was defined if the student(s) chose to start physiotherapy with additional medical evaluation (keep and refer) or refer the patient without physiotherapeutic management (refer). The sole correct answer for medical critical cases was the decision to send the patient for medical evaluation without physiotherapeutic management (refer).

In accordance with earlier methodology [16,18-20], vignettes number 3, 4, 6, 8, 10 were regarded as musculoskeletal, vignettes number 1, 2, 7, 11 were categorized as medical noncritical and vignettes 5, 9, 12 formed the medical critical category.

\section{Data analysis}

Data analysis was carried out using the Statistical Package for Social Sciences (SPSS) for windows version 22.0.0.2 (IBM, USA) and only students who completed all 12 vignettes were included in the final analysis.

Descriptive statistics were utilized to portray demographic characteristics of participating ENPHE member countries. Replicating previous methodology, descriptive statistics were also used to obtain the mean percentages (plus standard deviation) of correct keep/refer decisions and actual numbers as well as percentages of students who managed to accurately answer all vignettes from a specific category [16-20]. As small sample sizes for single countries were expected beforehand, the decision was made to also look at the median ( 25 and 75 percentiles) percentages of correct responses. Participating countries were additionally divided into three groups depending on whether they either have a direct access system (to physiotherapy), non-direct access system (to physiotherapy), or direct access system (to physiotherapy) but only for the private health care sector.

Measures of central tendency (mean and median), measurements of variability (standard deviation and percentiles) and percentages of students who managed to complete $100 \%$ of vignettes within a category were reported for all respondents combined and also for single countries. Mean (plus standard deviation) and median (25 and 75 percentiles) percentages of correct keep/refer decisions (for each category) depending on different access systems were calculated. 


\section{Results}

\section{Combined results for European final year undergraduate physiotherapy students}

Table 2 shows that correct keep/refer judgements for both the musculoskeletal and medical non-critical vignettes were made in more than $70 \%$ (on the average). Only slightly over $50 \%$ (on the average) of the medical critical cases were answered correctly (refer without providing physiotherapy intervention).

Descriptive analysis, as summarized in Table 3, furthermore revealed that $15.1 \%$ ( $n=11$ out of 73) respondents managed to correctly answer $100 \%$ of the cases in the musculoskeletal category. Furthermore, $19.2 \%(n=14$ out of 73$)$ and $11 \%(n=8$ out of 73$)$ of respondents made an accurate keep/refer decision for all cases in the medical non-critical and medical critical category, respectively.

\section{Results of individual ENPHE member countries}

The results from individual ENPHE member countries in Table 4 demonstrated the highest scores for the medical critical category by participants from the Czech Republic ( $n=4$, mean: 67\%, median: 67\%), the Netherlands ( $n=14$, mean: 62\%, median: 67\%) and Estonia $(n=10$, mean: $60 \%$, median: $67 \%$ ).

As seen in Table 5, there were very limited percentages of students from any country who managed to correctly answer all cases from a category. The Netherlands was the sole country who had more than one student $(n=3)$ who could properly answer all three medical critical vignettes.

\section{Results in relation to divergent access systems to physiotherapy within Europe}

Comparison of the mean and median percentages of accurate keep/refer decisions for the musculoskeletal and medical non-critical vignettes demonstrate only marginal differences between students from either a direct or non-direct access system. As summarized in Table 6, the most notable difference is the median percentage within the medical critical category which indicates a tendency towards a higher accuracy of students who were trained in a country with direct access (to physiotherapy) only for the private health sector.

\section{Discussion}

This is the first study to give an overview of how far final year undergraduate physiotherapy students from different European countries are capable of making correct keep/refer decisions 
when being given concise, clinical vignettes. European undergraduate physiotherapy student participants made a correct keep/refer judgement for both the musculoskeletal and medical non-critical vignettes in more than $70 \%$. However only slightly over $50 \%$ of the medical critical cases were answered correctly and participants chose to refer without providing physiotherapy intervention.

However and perhaps encouragingly, this is consistent with earlier reports on qualified physiotherapists and DPT students which also revealed a lack of knowledge to accurately detect severe pathological conditions [15-20]. A correct keep/refer decision for the medical critical cases was made (on the average) by Swiss physiotherapists in 67.1\% [20], by DPT students in the United States in 67.7\% [18], by qualified physiotherapists in Germany in $53.3 \%$ [19] and by qualified physiotherapists in the United States in 73.3\% [17] and 79\% [16] respectively. In the current project, an alarmingly low number of eight participants (11\%) managed to identify all three medical critical vignettes and correctly chose to refer the patient without giving any physiotherapy intervention.

It is beyond the scope of this paper to make a detailed comparative analysis of teaching curricula across European countries and Universities. Results from the Netherlands, the Czech Republic and Estonia, however, demonstrate an apparent trend towards a higher proportion of students who are capable of making an accurate keep/refer decision for the medical critical cases. A recent review by Lackenbauer et al. [14] revealed that the Dutch national guidelines for the physiotherapy profession very clearly demand their (qualified) physiotherapists to be capable of identifying pathologies which are not suitable for physiotherapy and therefore require a referral to another health care professional (e.g. a physician) [14]. Unfortunately, no similar data was found for educational or professional guidelines from Estonia.

Students' performances from the diverging access systems to physiotherapy services demonstrate a clear tendency that students from a direct access system to physiotherapy for the private health sector were generally more accurate in the identification of the medical critical vignettes. Interestingly and also surprisingly, those differences were absent when comparing correct keep/refer decisions for medical critical cases between students from countries with direct access (for the public and private sector) and those from countries without direct access to physiotherapy.

The low return rate of this study (3.3\%) makes generalizability of the results problematic, even for ENPHE member Universities. Having said this, the overall return rate in the current 
study is still in accordance with Vaughn et al. [18] whose response rate was also below 5\% and who used a similar approach to examine keep/refer decision making abilities of final year DPT students in the United States. As opposed to other authors [15-17,19,20], Vaughn et al. [18] were not able to directly distribute their survey among their study sample (final year DPT students). As in the current study, Vaughn et al. [18] had to rely on individual Universities to subsequently distribute the survey among the physiotherapy students.

Although this is the first study which provides a preliminary and cautious overview of keep/refer decision making competencies of final year undergraduate physiotherapy students from ten different European countries there are several limitations which need to be discussed: Firstly, the issue of social desirability bias as highlighted by Veloski et al. [21]. The authors argue that since study participants are aware of being under investigation, their response might represent a more idealistic decision which can substantially differ from what they would actually do during their daily routine. Another important issue applies to non response bias. Vaughn et al. [18], who examined keep/refer decision making abilities of DPT students, even hypothesized that individual Universities, who knew about a possible lack of knowledge/training of their students, might have been reluctant to distribute the survey. In addition, it is quite likely that students only completed the survey if they felt comfortable of making an accurate keep/refer decision based on clinical vignettes. Moreover, it can be hypothesized that some students had doubts about their ability to complete a survey which was entirely in English. The application of clinical vignettes is generally accepted as a valid method to investigate clinical decision making competencies within health care related research (especially in situations where the gold standard, real life patients, is infeasible) [2225]. In addition, the 12 vignettes used in the current study have already been validated on two different occasions by expert physiotherapists [16] and a panel of medical doctors [18]. Yet, not all vignettes could reach $100 \%$ consensus during the validation process [18]. This issue became especially obvious in vignette number ten. While this case was originally thought to describe a rather benign musculoskeletal health problem (costochondritis) [16], the emergency physician in Vaughn et al. [18] vehemently argued that the signs and symptoms described in vignette number 10 were also very typical for a myocardial infarct. Interestingly and perhaps reassuringly based on the report of Vaughn et al. [18], the bulk of students in the current study also deemed this case to be highly suspicious and chose to refer the patient without giving any physiotherapy intervention. 
The target population of final year undergraduate physiotherapy students was limited to students from some of the ENPHE member Universities only. ENPHE member institutions do not represent all Universities within Europe which offer an undergraduate degree in physiotherapy. As a direct consequence, the results cannot be used to make a generalized statement about keep/refer decision making abilities of European undergraduate physiotherapy students. In addition, it was not possible to obtain e-mail addresses from all 183 ENPHE member Universities, as it was not always clear which Universities actually are current ENPHE members due to inconsistencies on the ENPHE homepage and language barriers on the individual university websites. Furthermore, it was not feasible to convince all remaining ENPHE Universities to participate in the research study. Moreover, not all Universities listed detailed information such as the actual student number, graduation date(s), contact names and (e-mail) addresses. Some results of individual countries (as seen in Table 4) also give rise to doubt if students really completed the survey alone. Students were explicitly asked to finish the survey on an individual basis but there is no way of telling if they complied with this request. The last limitation concerns the possibility of making a correct keep/refer decision simply by chance. Two different answer options for the vignettes of the musculoskeletal (keep or keep/refer) and medical non critical category (keep/refer or refer) were considered correct. Conversely, there was no alternative other than referring the patient without any physiotherapy intervention (refer) for three the medical critical cases. This alone might be an explanation for the generally poorer results within the medical critical category (as seen in Table 2). While this is true, the possibility of coming across potential medical emergencies justifies a rather rigorous approach/decision without any other options for the treating physiotherapists.

In conclusion, novice physiotherapists are not expected to be as accurate as qualified and more experienced physiotherapists when it comes to clinical keep/refer decision making competencies. Novice physiotherapists, however, also work with patients (without supervision and, depending on the health care system, even without prior medical referral) and are therefore continuously challenged to independently determine if a patient is suitable for physiotherapy (as part of a professional and/or ethical obligation). And although the response rate was extremely low and therefore generalizability of the results is problematic, outcome data of the current project gives the clear impression that, in general, European final year undergraduate physiotherapy students are not sufficiently equipped with enough knowledge and skills to make very precise keep/refer decisions (based on clinical vignettes) and, most importantly, seem insufficiently trained to accurately identify more severe medical 
conditions which require a timely referral to another health care professional (e.g. a physician). Further research (especially with larger sample sizes) is needed to get a more complete picture of the keep/refer decision competencies of (final year) undergraduate physiotherapy students in Europe. Alternatively, the application of standardized patients [24] (possibly during clinical internships) may provide a more accurate, real life insight into the keep/refer decisions by undergraduate physiotherapy students in general. The introduction of the European Professional Card (EPC) simplified the process of physiotherapists working in different countries across Europe [26]. Therefore, a European wide consensus or standard that governs specific contents and lecturing hours spent on teaching students how to make accurate keep/refer decisions, as part of the undergraduate curriculum, is needed.

\section{Acknowledgements}

The authors would like to thank Dr Michael Weber for his statistical advice during the preparation of this manuscript. The authors are also grateful to Dr Ursula Eckler for her efforts to advertise the project during an ENPHE conference in 2015.

\section{Declaration of interest}

The authors report no declarations of interest.

\section{Reference list}

1. Greenhalgh S, Selfe J. Margaret: a tragic case of spinal Red Flags and Red Herrings. Physiother. 2004;90(2):73-76.

2. De Schepper EIT, Koes BW, Veldhuizen EFH, et al. Prevalence of spinal pathology in patients presenting for lumbar MRI as referred from general practice. Fam Pract. 2016;33(1):51-56.

3. Enthoven WTM, Geuze J, Scheele J, et al. Prevalence and „Red Flags“ Regarding Specific Causes of Back Pain in Older Adults Presenting in General Practice. Phys Ther. 2016;96(3):305-312.

4. Henschke N, Maher CG, Refshauge KM, et al. Prevalence of and Screening for Serious Spinal Pathology in Patients Presenting to Primary Spine Settings With Acute Low Back Pain. Arthritis Rheum. 2009;60(10):3072-3080.

5. Boissonnault WG, Ross MD. Physical therapists referring patients to physicians: a review of case reports and series. J Orthop Sports Phys Ther. 2012;42(5):446-454.

6. Rodeghero JR, Denninger TR, Ross MD. Abdominal pain in physical therapy practice: 3 patient cases. J Orthop Sports Phys Ther. 2013;43(2):44-53.

7. VanWyngaarden JJ, Ross MD, Hando BR. Abdominal aortic aneurysm in a patient with low back pain. J Orthop Sports Phys Ther. 2014;44(7):500-507.

8. Lackenbauer W, Janssen J. Lyme Disease as a Source of Chronic Cervical Spine Complaints Radiating into the Upper Extremity: Case Report. ManuelleTherapie. 2017;21:43-46.

9. Lackenbauer W, Janssen J. Gallstones as a Source of Muscular Thoracic Pain: Case Report. ManuelleTherapie. 2016;20:233-236. 
10. Hawkins AP, Sum JC, Kirages D, et al. Pelvic osteomyelitis presenting as groin and medial thigh pain: a resident's case problem. J Orthop Sports Phys Ther. 2015;45(4):306-315.

11. World Confederation for Physical Therapy. Standards of physical therapy practice. London, UK: WCPT; 2011. Available from: http://www.wcpt.org/guidelines/standards

12. World Confederation for Physical Therapy. WCPT guideline for physical therapist professional entry level education. London, UK: WCPT; 2011. Available from: http://www.wcpt.org/guidelines/entry-level-education

13. World Confederation for Physical Therapy. Policy Statement: Education. London, UK: WCPT; 2011. Available from: http://www.wcpt.org/policy/ps-education

14. Lackenbauer W, Janssen J, Roddam H, et al. Is keep/refer decision making an integral part of national guidelines for the physiotherapy profession within Europe? A review. Physiother. 2016 [cited 2017 Jul 1]; [22 p]. DOI: https://doi.org/10.1016/j.physio.2016.11.005

15. Riddle LD, Hillner BE, Wells PS, et al. Diagnosis of Lower- Extremity Deep Vein Thrombosis in Outpatients with Musculoskeletal Disorders: A National Survey Study of Physical Therapists. Phys Ther. 2004;84(8):717-728.

16. Jette DU, Ardleigh K, Chandler K, et al. Decision-Making Ability of Physical Therapists: Physical Therapy Intervention or Medical Referral. Phys Ther. 2006;86(12):1619-1629.

17. Mount HE. SCREENING FOR MEDICAL REFERRAL: DETERMINING VARIABLES THAT INFLUENCE ACCURACY [dissertation]. Birmingham (Alabama). University of Alabama; 2012.

18. Vaughn DW, Shoemaker MJ, DaPrato D, et al. The Ability of Final-Year Doctor of Physical Therapy Students to Make Keep/Refer Decisions. J Phys Ther Educ; 2011;25(3):60-67.

19. Beyerlein C. Direktzugang in der Physiotherapie - Wie entscheiden sich Physiotherapeuten im Management ihrer Patienten [dissertation]. Ulm (Baden-Württemberg). Universitätsklinikum Ulm; 2010.

20. Schämann A, Scheermesser M, Stegen C, et al. Direktzugang zur Physiotherapie in der Schweiz. ' Paper presented at: Bildungs- und Unternehmerforum; 2011 September 30; Bern.

21. Veloski J, Tai S, Evans A, et al. Clinical Vignette-Based Surveys: A Tool for Assessing Physician Practice Variations. Am J Med Qual. 2005;20(3);151-157.

22. Peabody JW, Luck J, Glassman P, et al. Comparison of Vignettes , Standardized Patients, and Chart Abstraction: A Prospective Validation Study of 3 Methods for Measuring Quality. JAMA. 2000;283(13):1715-1722.

23. Peabody JW, Luck J, Glassman P, et al. Measuring the Quality of Physician Practice by Using Clinical Vignettes: A Prospective Validation Study. Ann Intern Med. 2004;141(10):771-780.

24. Converse L, Barrett K, Rich E, et al. Methods of Observing Variations in Physcians ${ }^{6}$ Decisions: The Opportunities of Clinical Vignettes. J Gen Intern Med. 2015 [cited 2017 Jul 2]; [9 p.]. DOI: $10.1007 / \mathrm{s} 11606-015-3365-8$

25. Rousseau A, Rozenberg P, Ravaud P. Assessing Complex Emergency Management with Clinical Case-Vignettes: A Validation Study. PLoS ONE. 2015 [cited 2017 Jul 3]; [12 p.]. DOI:10.1371/journal.pone.0138663

26. The European Professional Card (EPC): have your qualifications recognized abroad - Your Europe [Internet]; [cited 2017 Oct 4]. Available from: http://europa.eu/youreurope/citizens/work/professional-qualifications/european-professionalcard/index_en.htm 
Table 1: Demographic characteristics of participating ENPHE member countries.

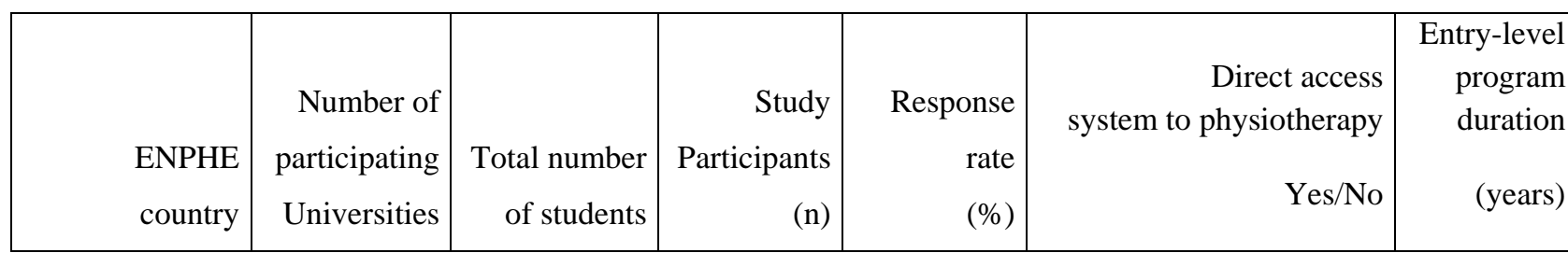

\begin{tabular}{|c|c|c|c|c|c|}
\hline Austria & 4 & 284 & 13 & 4.6 & No \\
\hline Belgium & 1 & 250 & 0 & 0 & No \\
\hline Czech Republic & 1 & 38 & 4 & 10.5 & Yes (private sector only) \\
\hline Denmark & 4 & 211 & 16 & 7.5 & Yes (private sector only) \\
\hline Estonia & 1 & 30 & 10 & 33.3 & Yes (private sector only) \\
\hline Finland & 4 & 151 & 6 & 4 & Yes \\
\hline Germany & 3 & 71 & 2 & 2.8 & No \\
\hline Latvia & 1 & 10 & 0 & 0 & Yes (private sector only) \\
\hline Lithuania & 3 & 196 & 1 & 0.5 & Yes (private sector only) \\
\hline Netherlands & 4 & 410 & 14 & 3.4 & Yes (private sector only) \\
\hline Norway & 1 & 40 & 0 & 0 & Yes (private sector only) \\
\hline Spain & 3 & 223 & 4 & 1.8 & Yes (private sector only) \\
\hline Sweden & 3 & 123 & 3 & 2.4 & Yes \\
\hline Switzerland & 1 & 111 & 0 & 0 & Yes (private sector only) \\
\hline United & 2 & 90 & 0 & 0 & Yes \\
\hline
\end{tabular}

Kingdom 
Table 2: Mean and median percentages of correct keep/refer decisions (of European undergraduate physiotherapy students combined) for each category.

Mean

Median

Standard deviation

Percentiles

\begin{tabular}{|r|r|r|}
\hline Musculoskeletal & Medical non critical & Medical critical \\
\hline $75 \%$ & $72 \%$ & $52 \%$ \\
$80 \%$ & $75 \%$ & $67 \%$ \\
$17 \%$ & $20 \%$ & $28 \%$ \\
$60 \%$ & $50 \%$ & $33 \%$ \\
$80 \%$ & $75 \%$ & $67 \%$ \\
\hline
\end{tabular}


Table 3: Percentages of European undergraduate physiotherapy students (combined) who made a correct (YES) or incorrect (NO) keep/refer decision for $100 \%$ of cases within a category.

\begin{tabular}{|cc|lc|lc|}
\hline $\begin{array}{l}\text { Musculoskeletal } \\
100 \% \text { correct }\end{array}$ & & $\begin{array}{l}\text { Medical } \\
\text { non critical } \\
100 \%\end{array}$ & & $\begin{array}{l}\text { Medical } \\
\text { critical } \\
100 \% \\
\text { correct }\end{array}$ & Yorrect \\
\hline No & Yes & No & Yes & No & Yes \\
$84.9 \%$ & $15.1 \%$ & $80.8 \%$ & $19.2 \%$ & $89.0 \%$ & $11.0 \%$
\end{tabular}


Table 4: Mean and median percentages of correct keep/refer decisions for each category (per country).

\begin{tabular}{|c|c|c|c|c|c|}
\hline Countries & & & Musculoskeletal & $\begin{array}{c}\text { Medical } \\
\text { non critical }\end{array}$ & $\begin{array}{c}\text { Medical } \\
\text { critical }\end{array}$ \\
\hline \multirow{5}{*}{ Austria } & Mean & & $77 \%$ & $73 \%$ & $46 \%$ \\
\hline & Median & & $80 \%$ & $75 \%$ & $33 \%$ \\
\hline & Standard De & & $16 \%$ & $12 \%$ & $26 \%$ \\
\hline & \multirow{2}{*}{ Percentiles } & 25 & $70 \%$ & $75 \%$ & $33 \%$ \\
\hline & & 75 & $80 \%$ & $75 \%$ & $67 \%$ \\
\hline \multirow{5}{*}{ Czech Republic } & Mean & & $50 \%$ & $94 \%$ & $67 \%$ \\
\hline & Median & & $50 \%$ & $100 \%$ & $67 \%$ \\
\hline & Standard De & & $12 \%$ & $13 \%$ & $0 \%$ \\
\hline & Percentiles & 25 & $40 \%$ & $81 \%$ & $67 \%$ \\
\hline & rercentintes & 75 & $60 \%$ & $100 \%$ & $67 \%$ \\
\hline \multirow{5}{*}{ Denmark } & Mean & & $81 \%$ & $64 \%$ & $46 \%$ \\
\hline & Median & & $80 \%$ & $75 \%$ & $33 \%$ \\
\hline & Standard De & & $11 \%$ & $22 \%$ & $21 \%$ \\
\hline & \multirow{2}{*}{ Percentiles } & 25 & $80 \%$ & $50 \%$ & $33 \%$ \\
\hline & & 75 & $80 \%$ & $75 \%$ & $67 \%$ \\
\hline \multirow{5}{*}{ Estonia } & Mean & & $66 \%$ & $75 \%$ & $60 \%$ \\
\hline & Median & & $60 \%$ & $75 \%$ & $67 \%$ \\
\hline & Standard De & & $13 \%$ & $20 \%$ & $21 \%$ \\
\hline & \multirow{2}{*}{ Percentiles } & 25 & $60 \%$ & $50 \%$ & $33 \%$ \\
\hline & & 75 & $80 \%$ & $100 \%$ & $67 \%$ \\
\hline \multirow{5}{*}{ Finland } & Mean & & $67 \%$ & $67 \%$ & $56 \%$ \\
\hline & Median & & $70 \%$ & $75 \%$ & $50 \%$ \\
\hline & Standard De & & $27 \%$ & $13 \%$ & $27 \%$ \\
\hline & \multirow{2}{*}{ Percentiles } & 25 & $50 \%$ & $50 \%$ & $33 \%$ \\
\hline & & 75 & $85 \%$ & $75 \%$ & $75 \%$ \\
\hline \multirow{5}{*}{ Germany } & Mean & & $80 \%$ & $88 \%$ & $50 \%$ \\
\hline & Median & & $80 \%$ & $88 \%$ & $50 \%$ \\
\hline & Standard De & & $28 \%$ & $18 \%$ & $24 \%$ \\
\hline & \multirow{2}{*}{ Percentiles } & 25 & $60 \%$ & $75 \%$ & $33 \%$ \\
\hline & & 75 & . & . & \\
\hline \multirow{4}{*}{ Lithuania } & Mean & & $100 \%$ & $100 \%$ & $0 \%$ \\
\hline & Median & & $100 \%$ & $100 \%$ & $0 \%$ \\
\hline & \multirow{2}{*}{ Percentiles } & 25 & $100 \%$ & $100 \%$ & $0 \%$ \\
\hline & & 75 & $100 \%$ & $100 \%$ & $0 \%$ \\
\hline \multirow{4}{*}{ Netherlands } & Mean & & $77 \%$ & $73 \%$ & $62 \%$ \\
\hline & Median & & $80 \%$ & $75 \%$ & $67 \%$ \\
\hline & Standard De & & $13 \%$ & $21 \%$ & $32 \%$ \\
\hline & Percentiles & 25 & $60 \%$ & $69 \%$ & $58 \%$ \\
\hline
\end{tabular}




\begin{tabular}{|c|c|c|c|c|c|}
\hline & & 75 & $80 \%$ & $81 \%$ & $75 \%$ \\
\hline \multirow{5}{*}{ Spain } & Mean & & $85 \%$ & $63 \%$ & $50 \%$ \\
\hline & Median & & $80 \%$ & $75 \%$ & $50 \%$ \\
\hline & Standard De & & $10 \%$ & $25 \%$ & $43 \%$ \\
\hline & \multirow{2}{*}{ Percentiles } & 25 & $80 \%$ & $38 \%$ & $10 \%$ \\
\hline & & 75 & $95 \%$ & $75 \%$ & $92 \%$ \\
\hline \multirow{5}{*}{ Sweden } & Mean & & $80 \%$ & $67 \%$ & $33 \%$ \\
\hline & Median & & $80 \%$ & $75 \%$ & $0 \%$ \\
\hline & Standard De & & $0 \%$ & $14 \%$ & $58 \%$ \\
\hline & \multirow{2}{*}{ Percentiles } & 25 & $80 \%$ & $50 \%$ & $0 \%$ \\
\hline & & 75 & & & \\
\hline
\end{tabular}


Table 5: Percentages of students (per country) who made a correct (Yes) or incorrect (No) keep/refer decision for $100 \%$ of cases within a category.

\begin{tabular}{|c|c|c|c|c|c|c|}
\hline \multirow[t]{2}{*}{ Countries } & \multicolumn{2}{|c|}{$\begin{array}{l}\text { Musculoskeletal } 100 \% \\
\text { correct }\end{array}$} & \multicolumn{2}{|c|}{$\begin{array}{c}\text { Medical non critical } 100 \% \\
\text { correct }\end{array}$} & \multicolumn{2}{|c|}{$\begin{array}{l}\text { Medical critical100\% } \\
\text { correct }\end{array}$} \\
\hline & No & Yes & No & Yes & No & Yes \\
\hline Austria & $84.6 \%$ & $15.4 \%$ & $92.3 \%$ & $7.7 \%$ & $92.3 \%$ & $7.7 \%$ \\
\hline $\begin{array}{l}\text { Czech } \\
\text { Republic }\end{array}$ & $100.0 \%$ & $0.0 \%$ & $25.0 \%$ & $75.0 \%$ & $100.0 \%$ & $0.0 \%$ \\
\hline Denmark & $81.3 \%$ & $18.8 \%$ & $87.5 \%$ & $12.5 \%$ & $100.0 \%$ & $0.0 \%$ \\
\hline Estonia & $100.0 \%$ & $0.0 \%$ & $70.0 \%$ & $30.0 \%$ & $90.0 \%$ & $10.0 \%$ \\
\hline Finland & $83.3 \%$ & $16.7 \%$ & $100.0 \%$ & $0.0 \%$ & $83.3 \%$ & $16.7 \%$ \\
\hline Germany & $50.0 \%$ & $50.0 \%$ & $50.0 \%$ & $50.0 \%$ & $100.0 \%$ & $0.0 \%$ \\
\hline Lithuania & $0.0 \%$ & $100.0 \%$ & $0.0 \%$ & $100.0 \%$ & $100.0 \%$ & $0.0 \%$ \\
\hline Netherlands & $85.7 \%$ & $14.3 \%$ & $78.6 \%$ & $21.4 \%$ & $78.6 \%$ & $21.4 \%$ \\
\hline Spain & $75.0 \%$ & $25.0 \%$ & $100.0 \%$ & $0.0 \%$ & $75.0 \%$ & $25.0 \%$ \\
\hline Sweden & $100.0 \%$ & $0.0 \%$ & $100.0 \%$ & $0.0 \%$ & $66.7 \%$ & $33.3 \%$ \\
\hline
\end{tabular}


Table 6: Mean and median percentages of correct keep/refer decisions (depending on access system to physiotherapy) for each category.

\begin{tabular}{|c|c|c|c|c|c|}
\hline $\begin{array}{l}\text { Access } \\
\text { system }\end{array}$ & & & Musculoskeletal & Medical non critical & Medical critical \\
\hline \multirow{5}{*}{$\begin{array}{l}\text { no direct } \\
\text { access }\end{array}$} & Mean & & $77 \%$ & $75 \%$ & $47 \%$ \\
\hline & Median & & $80 \%$ & $75 \%$ & $33 \%$ \\
\hline & Std. Deviation & & $17 \%$ & $13 \%$ & $25 \%$ \\
\hline & \multirow{2}{*}{ Percentiles } & 25 & $60 \%$ & $75 \%$ & $33 \%$ \\
\hline & & 75 & $80 \%$ & $75 \%$ & $67 \%$ \\
\hline \multirow{5}{*}{$\begin{array}{l}\text { direct access } \\
\text { only private }\end{array}$} & Mean & & $75 \%$ & $72 \%$ & $54 \%$ \\
\hline & Median & & $80 \%$ & $75 \%$ & $67 \%$ \\
\hline & Std. Deviation & & $16 \%$ & $22 \%$ & $27 \%$ \\
\hline & \multirow{2}{*}{ Percentiles } & 25 & $60 \%$ & $50 \%$ & $33 \%$ \\
\hline & & 75 & $80 \%$ & $88 \%$ & $67 \%$ \\
\hline \multirow{5}{*}{ direct access } & Mean & & $71 \%$ & $67 \%$ & $48 \%$ \\
\hline & Median & & $80 \%$ & $75 \%$ & $33 \%$ \\
\hline & Std. Deviation & & $23 \%$ & $13 \%$ & $38 \%$ \\
\hline & \multirow{2}{*}{ Percentiles } & 25 & $60 \%$ & $50 \%$ & $17 \%$ \\
\hline & & 75 & $80 \%$ & $75 \%$ & $83 \%$ \\
\hline
\end{tabular}


Caption Figure 1: Different stages of recruitment. 